\title{
31 COLLABORATION BETWEEN ACADEMICS AND PRACTITIONERS USING ACTION RESEARCH
}

\author{
Frank Land \\ London School of Economics \\ United Kingdom \\ Lars Mathiassen \\ Aalborg University \\ Denmark \\ Bob Galliers \\ London School of Economics \\ United Kingdom \\ Mike Cushman \\ London School of Economics \\ United Kingdom
}

Richard Baskerville

Georgia State University

U.S.A.

There is much discussion among IS academics in general and those who belong to IFIP WG 8.2 in particular of appropriate research methods and their underlying philosophical foundations. Discussion on research methods has tended to focus on the debate between those who advocate empirical methods based on validating models, frameworks, and hypotheses by means of surveys buttressed by an array of statistical tests, and the advocates of interpretive, qualitative research based on observation, interviews, and case studies. The debate has resulted in the publication of a comprehensive literature, part of which questions the validity of one or other of the approaches, but part of which attempts to define under what circumstances each is appropriate. Yet other discussants suggest the virtues of pluralistic approaches. 
However, there is a style of research widely used that has received rather less attention in the literature. The research involves collaboration between one or more academic groups working with a group of practitioners from one or more enterprises or public sector departments. The research questions typically addressed relate to issues of practice, with an emphasis on the research team developing improvements in the way things are done. The research is normally situated in the real world, rather than in an experimental or simulated world. The practitioner elements of the research team are mostly directly involved as part of their normal working life in the work area being studied.

Because the research attempts to improve "living" practice, the research team has to intervene in the actual processes used, hence the notion of action research. Of course, like the other research methods, the researchers have to attempt to explain the outcomes of their interventions, either basing these on theoretical foundations or using a grounded theory approach, developing theories from an analysis of the outcomes.

As in much IS research, major issues revolve around issues of relevance, validation, and generalization. Indeed, some social researchers question the legitimacy of this type of research, although the issue of relevance is rarely raised.

It is felt that collaborative action research is an important weapon in the research armory and some of its chief advocates will set out the case for the approach and its role in IS research, and will discuss the important issues of method, relevance, validation, and generalization. A case study of a completed research project will be published on the conference website and all those who wish to come to the panel should come prepared by having read the case. Mike Cushman, who was lead researcher of the project, will remind attendees of some of the issues arising from the research.

The B-Hive (Building a High Value Construction Environment) Project was a UK joint industry/academic research project running from 1997 to 1999 . The project was managed by one of the construction industry partners, rather than a university. The project brief required the participants to, "Demonstrate by application on selected live projects, how emerging information and communication technologies can support restructured project organizations that are committed to continuous value improvement." An action-research approach was prescribed in the original project proposal.

The main product of the research was a process designed to enable managerial reflection upon critical incidents in construction projects involving managers from all of the key contract companies called COLA (CrossOrganizational Learning Approach). This was not an outcome anticipated by any of the B-Hive participants and could only have been achieved through the iteration through repeated stages of intervention, reflection, and adaptation 
permitted by an action-research approach. The mutual education of university and construction company staff and the, at times, onerous processes required to maintain continued ownership of process allowed for radical redefinition of both the problem and the permissible solutions. In particular when the initial surveys showed low levels of adoption of ICTs in the industry, it allowed focus to shift to innovative processes for the use of less sophisticated technologies such as e-mail, Microsoft Office applications, and digital cameras rather than the creation of more advanced artefacts that would have little chance of adoption within the industry environment.

\section{REFERENCES}

Galliers, R. D, and Land, F. F. "Choosing Appropriate Information Systems Research Methodologies," Communications of the ACM (30:11), November 1987.

Matthiassen, L. "Collaborative Practice Research" in Organizational and Social Perspectives on Information Technology, R. Baskerville, J. Stage, and J. I. DeGross (eds.), Boston: Kluwer Academic Publishers, 2000, pp. 127-148.

\section{About the Panelists}

Frank Land was educated at the London School of Economics. After a short period of research in economics, he joined the British food company $\mathrm{J}$ Lyons in 1952. Lyons had just commissioned the world's first computer designed for business data processing - the LEO - and he was fortunate enough to be selected to become a member of the LEO team. He stayed with LEO as programmer, systems analyst, and consultant until 1967. In that year he returned to the London School of Economics with a government grant to establish teaching and research in "systems analysis." He was promoted to Professor of Systems Analysis in 1982 and Professor of Information Management at the London Business School in 1986. He has been Visiting Professor at the Wharton School, University of Sydney, Cairo University, Bond University, and Curtain University. Frank formally retired in 1992 but is currently Visiting Professor of Information Management at the London School of Economics and at Leeds Metropolitan University. He acted as technical advisor to the House of Commons Select Committee on Industry and Trade in its two year enquiry into the UK IT industry. He has co-authored papers on IS research methodologies (Galliers and Land 1987). Frank can be reached by e-mail at flandlse@aol.com

Bob Galliers is Professor of Information Systems at the London School of Economics where he is Research Professor in the Department of Information 
Systems. He was previously Professor of Information Management at Warwick Business School, where he was Dean for the period 1994-1998. He is also currently Gemini Visiting Professor of Knowledge Management at the University of St Gallen, Switzerland, having previously been Visiting Professor of Information Systems at INSEAD, France, for the academic year 1998/99. His research is transdisciplinary in nature and currently focuses on information technology and business innovation, business transformation, and the management of change; and information systems strategy, strategy alignment, knowledge creation, and management and intra- and extra-organizational impacts of the Internet. Bob started his career in IS working with Professor Peter Checkland on a number of assignments using the action research approach. He can be reached by e-mail at r.d.galliers@1se.ac.uk.

Lars Mathiassen is Professor in the Computer Science Department at Aalborg University, Denmark. His research area is Information Systems Development and he has practiced action research within this area for more than 25 years. One of his recent contributions, "Collaborative Practice Research," appeared in the proceedings of the last 8.2 Conference, Aalborg, June, 2000 (Mathiassen 2000). Lars can be reached by e-mail at larsm@cs.auc.dk.

Mike Cushman is currently the Information Manager for the Department of Information Systems at the London School of Economics. He was the lead research officer for the B-Hive (Building a Higher Value Construction Environment) project, an action research project involving two universities and five construction firms. Before becoming involved in information systems, his previous career was in adult education, where he was head of a large inner London service. As part of his adult education career, he was involved in action research projects to develop new community focused curricula and methods of service delivery and negotiation. Mike can be reached by e-mail at m.cushman@1se.ac.uk.

Richard Baskerville is Professor and Chairman in the Department of Computer Information Systems at Georgia State University. His research focuses on security and methods in information systems, their interaction with organizations, and research methods. He is particularly interested in action research and is the author of numerous articles on this topic. He is an active associate editor, having worked with The Information Systems Journal and MIS Quarterly. Baskerville's practical and consulting experience includes advanced information system designs for the U.S. Defense and Energy Departments, where action research was used for technology transfer. He is a former chair of the IFIP Working Group 8.2, and a Chartered Engineer under the British Engineering Council. Richard holds M.Sc. and Ph.D. degrees from the London School of Economics. He can be reached by e-mail at baskerville@acm.org. 